\title{
La violencia contra las personas sexo-género diverso su tratamiento en el sistema jurídico venezolano
}

\author{
Violence against people of different sexes, their treatment in the \\ venezuelan legal system
}

Juan Carlos Araujo-Cuauro*

\begin{abstract}
Resumen
La violencia motivada contra las personas género-sexo diverso, constituye hoy en día a una violación a los derechos humanos de tercera generación como lo son los derechos sexuales. El propósito de la investigación es hacer un análisis reflexivo sobre el tratamiento que el ordenamiento jurídico venezolano a través de sus instituciones, le brinda al grupo de personas que integran la comunidad de Lesbianas, Gays, Bisexuales, Trans e intersex (LGBTI), tomando como principales documentos la normativa existente en la legislación venezolana promulgadas por la Constitución (Asamblea Nacional, 1999), Ley Orgánica sobre el Derecho de las Mujeres a una Vida Libre de Violencia (Asamblea Nacional, 2007), Anteproyecto de Ley Orgánica de Equidad e Igualdad de Género (Asamblea Nacional, 2010), Código Penal de Venezuela (Asamblea Nacional, 2005), Código de Instrucción Médico Forense (Congreso de los Estados Unidos de Venezuela, 1878), Código de Deontología Médica(Federación Médica Venezolana, 2003),enfocándolo desde el punto de vista jurídico legal y así mismo intentado establecer las directrices razonables éticasmorales, que orienten la actitud de la sociedad en general. La violencia de género puede ser un tipo de violencia física o psicológica ejercida contra cualquier persona sobre la base de su sexo o género que impacta de manera negativa su identidad y bienestar social, físico o psicológico, como en el caso de las personas sexo-género diversos (LGBTI). Fue implementado el método analítico-sintético para la realización de la investigación por medio de una revisión documental bibliográfica. Se concluye que los derechos sexuales son derechos humanos universales basados en la libertad inherente, dignidad e igualdad para todos los seres humanos. Así mismo se puede constatar que en todo el mundo hay personas que se enfrentan a un elevado nivel de violencia y discriminación por su orientación sexual y su identidad de género y nuestro país no escapa de esta realidad.
\end{abstract}

\footnotetext{
*Médico, Abogado. Profesor de Medicina Legal. Facultad de Ciencias Jurídicas y Políticas. Universidad del Zulia (LUZ). Av. 16 (Guajira). Ciudad Universitaria "Dr. Antonio Borjas Romero", Núcleo Humanístico. Maracaibo-Venezuela. Correo electrónico: jcaraujoc_65@hotmail.com; jcaraujoc95@gmail.com.
} 
La violencia contra las personas sexo-género diverso su tratamiento en el sistema jurídico venezolano

Palabras clave: Violencia, sexo-género diversas, personas, lesbianas, gais, bisexuales, transgénero, intersex.

RECIBIDO: Abril 2017 ACEPTADO: Noviembre 2017

\begin{abstract}
The motivated violence against the diverse sex-gender people constitutes today a violation of the third generation human rights such as sexual rights. The purpose of the research is to make a reflexive analysis about the treatment that the Venezuelan legal system through its institutions, provides to the group of people that make up the Lesbian, Gay, Bisexual, Trans and Intersex community (LGBTI), taking as main documents the existing legislation in Venezuelan legislation as the Constitution (National Assembly. 1999), Organic Law on the Right of Women to a Life Free of Violence (National Assembly, 2007), Draft Organic Law on Equality and Gender Equality (National Assembly, 2010), Penal Code of Venezuela (National Assembly, 2005), Code of Forensic Medical Instruction (Congress of the United States of Venezuela, 1878), focusing it from the legal point of view and also trying to establish reasonable guidelines s ethical-moral, that guide the attitude of society in general. Gender violence can be a type of physical or psychological violence against any person based on their sex or gender that negatively impacts their identity and social, physical or psychological well-being, as in the case of sex-gender people diverse (LGBTI). The analytical-synthetic method was implemented to carry out the research through a bibliographic documentary review. It is concluded that sexual rights are universal human rights based on inherent freedom, dignity and equality for all human beings. Likewise, it can be seen that throughout the world there are people who face a high level of violence and discrimination because of their sexual orientation and gender identity and our country does not escape this reality.
\end{abstract}

Key words: Violence, diverse sex-gender, people, lesbian, gay, bisexual, transgender, intersex.

\title{
Introducción
}

La sociedad mundial globalizada se encuentra organizada desde una perspectiva homogeneizadora, es decir, busca que las personas que conforman posean característica, comportamiento y creencias comunes, considerando que dicha 
composición y cohesión social contribuya a evitar conflictos sociales e inclusive legales generados por la orientación sexual y/o identidad de género de las personas.

El género es una categoría de análisis que permite conocer la forma como se construye lo femenino y lo masculino en un tiempo y en un espacio determinado y las relaciones que se establecen entre mujeres y hombres. El género se refiere a las ideas y expectativas (normas) extensamente compartidas con respecto a mujeres y hombres. Estas incluyen las ideas sobre características y habilidades "típicamente" consideradas masculinas y femeninas y expectativas comúnmente compartidas acerca de cómo deben comportarse las mujeres y los hombres en diversas situaciones.

La violencia es un concepto de múltiples dimensiones y connotaciones, que de acuerdo a la Organización Mundial de la Salud incluye el uso intencional de fuerza, poder físico, o amenazas, en contra de uno mismo, otra persona, o en contra de un grupo o comunidad, cuyo resultado desemboca con alta probabilidad en lesiones, muerte, secuelas psicológicas, o mal comportamiento.

Entonces la violencia como fenómeno social es sumamente compleja, donde actúan múltiples factores como lo son: lo biológico, psicológico, social, cultural, económico, político e incluso lo religioso (Gómez, 2012).

La historia de la humanidad está cargada de pasajes sobre el maltrato a los individuos producto a su orientación sexual como lo es la comunidad de personas sexo-genero diversidad, término que reconoce la existencia de una multiplicidad de vidas en la sociedad y una variedad de orientaciones, expresiones e identidades que contienen cargas afectivas, de género y sexuales de y entre las personas. Lesbianas, Gays, Bisexuales, Trans e intersex.

El Maltrato a personas sexo-genero diverso (LGBTI), está directamente relacionado con la violencia intrafamiliar, entendiéndose por ella como: "todas las formas de abuso que tienen lugar en las relaciones entre los miembros de una familia, considerando como relación de abuso toda conducta que por acción u omisión ocasiona dado físico y/o psicológico a otros miembros de la familia (Aguilar, 2015). 
La violencia contra las personas sexo-género diverso su tratamiento en el sistema jurídico venezolano

Junto a este concepto clásico, en la actualidad habría que incluir otras formas de malos tratos que se podrían encuadrar bajo el título de "crueldad al intersex", y que incluirían la explotación, el ensañamiento terapéutico, es decir violencia médica, las agresiones a los intersex por motivaciones políticas, religiosa, raza, entre otros (Gómez, 2012).

La temática sobre la Sexualidad Humanaa representado desde los inicios de la humanidad como un tema de tabú, sin embargo, con la declaración de los derechos sobre la sexualidad, el punto en cuestión de la Diversidad Sexual y la Diversidad de Género lo deja de ser.

A este respecto la sexualidad se experimenta y expresa a través de pensamientos, fantasías, deseos, creencias, actitudes, valores, comportamientos, prácticas y relaciones. Los derechos sexuales promueven la libertad de decidir y ejercer plenamente la sexualidad. Todas las personas somos intrínsecamente sexuales, y el desarrollo sexual evoluciona durante la infancia y la adolescencia, manifestándose durante el resto de las etapas de la vida.

En líneas generales los derechos sexuales emanan de los derechos a la libertad, igualdad, privacidad, autonomía, integridad y dignidad de todas las personas, sin embargo este derecho a la sexualidad ha sido objeto de regulación por el Derecho desde tiempos inmemoriales, ya sea para justificar la naturalidad de ciertas prácticas sexuales que fueron consideradas "naturales" o "normales" (por ejemplo, las relaciones heterosexuales que se producen al interior del matrimonio), siempre y cuando tuvieran por finalidad la reproducción humana, o para reprimir la realización de otro tipo de prácticas sexuales, que fueron caracterizadas como contrarias a la naturaleza (por ejemplo, la homosexualidad).

Atendiendo estas consideraciones, se entiende por diversidad corporal, a una amplia gama de representaciones del cuerpo, por ejemplo, variaciones en la anatomía sexual que se expanden más allá del binario hombre/mujer. En donde el término Intersex es una especie de sombrilla que abarca esta diversidad corporal. 
En consecuencia, el sexo-género diverso, hace referencia al término que reconoce la existencia de una multiplicidad de vidas en la sociedad y una variedad de orientaciones, expresiones e identidades que contienen cargas afectivas, de género y sexo entre las personas como lo son el grupo de personas; Lesbianas, Gais, Bisexuales, Trans e intersex (LGBTI).

En torno a las personas lesbianas, son las mujeres que se sienten emocional, sexual y románticamente atraídas a otras mujeres. Mientras que los hombres gais, son aquellas personas que se sienten emocional, sexual y románticamente atraídos a otros hombres.

Con respecto a los individuos bisexuales, son las que se sienten emocional, sexual y románticamente atraídas a hombres y mujeres. El cual no debe confundirse con los individuos trans, ya que estos son en donde la identidad de género de la persona no corresponde con el sexo asignado al nacer. Las personas trans construyen su identidad independientemente de tratamiento médico o intervenciones quirúrgicas.

Según la International Commission of Jurists, Sexual Orientation, Gender Identity and International Human Rights Law del año 2009, esta define a los individuos intersex, como todas aquellas situaciones en las que la anatomía sexual del individuo no se ajusta físicamente a los estándares culturalmente definidos para el cuerpo femenino o masculino (Hammarberg, 2009).

Resulta asimismo interesante hacer referencia sobre dos grupos de individuos denominados genero Queer, que es un término general para las personas cuya identidad de género no está incluida o trasciende el binario hombre y mujer y las personas, y el grupo Cisgénero, cuando la identidad de género de la persona corresponde con el sexo asignado al nacer. El prefijo cis es antónimo del prefijo trans (Lamas, 2002)

El propósito de la investigaciones hacer un análisis reflexivo sobre el tratamiento que el ordenamiento jurídico venezolano a través de sus instituciones, a esta situación tan problemática como lo es la violencia debido a la orientación sexual 
La violencia contra las personas sexo-género diverso su tratamiento en el sistema jurídico venezolano

o de género, sobre al grupo de personas de la comunidad integrada por personas; Lesbianas, Gays, Bisexuales, Trans e intersex (LGBTI), así mismo intentar establecer directrices razonables, éticas y legales, que orienten la actitud de la sociedad en general.

\section{El sexo como construcción socio-cultural y generador de problemas de violencia social}

El desarrollo del componente "sexo" como construcción sociocultural en la literatura académica queer e intersex, y que es clave para comprender las violaciones de los derechos humanos de las personas intersex.

Si bien es cierto que el concepto de sexo trasciende más allá de lo masculino o femenino, como un hecho biológico, es por esto que la teoría, sobre la asignación del sexo no es un hecho biológico innato; más bien, al individuo se les asigna un sexo social al nacer en base en la percepción que otros individuos tienen sobre área genital (Cabral, 2003).

Generalmente en la mayoría de los casos los individuos son fácilmente clasificados como niño o niña, algunas presentaciones del cuerpo son percibidos como ambiguos, y el proceso de asignación sexual no es inmediato.

Por una parte, el sexo anatómico presenta su propia presunta dicotomía, ya que puede ser producto de una lectura ideológica”. Mientras que, por otra parte, encasillar o clasificar a un ser humano como masculino o femenino es una decisión enteramente social (Rey, 2001).

Se puede emplear el conocimiento científico como ayuda al momento de tener que tomar la decisión, pero sólo nuestras creencias sobre el género no la ciencia puede definir nuestro sexo. Es por ello que nuestras creencias sobre el termino género afectan de entrada, qué tipo de conocimiento los científicos pueden producir sobre el sexo.

Esta percepción ideológica de género predeterminada sobre la ojeada del área genital, no permite disertar sobre un sexo natural, y por lo que es lo suficientemente 
fuerte como para "someter los cuerpos cuando no se adaptan cómodamente a la lectura que se espera hacer de ellos socialmente.

Pero resulta asimismo interesante que en los casos de personas intersex, a pesar de que la ciencia médica puede tomar en cuenta factores biológicos, frecuentemente la asignación sexual al nacer es el resultado de consideraciones socioculturales como el correcto tamaño del pene o la correcta capacidad de la vagina (Cabral, 2003).

Consecuentemente, el concepto de intersexualidad se ha desarrollado para describir un sin número de situaciones en las que el cuerpo sexuado de un individuo varía respecto al standard de corporalidad femenina o masculina socioculturalmente aceptado. Cabe considerar, por otra parte, que al concepto de intersex, se le incorporan otras definiciones que explican que las personas intersex nacen con variaciones en las características sexuales físicas, incluyendo características genéticas, hormonales o anatómicas atípica, debido a que a la diversidad corporal se refiere a una amplia gama de presentaciones del cuerpo que varían del cuerpo estándar producto de la variaciones en la anatomía sexual que van más allá de las concepciones culturales y sociales de cómo deben ser los cuerpos femeninos y masculinos.

Las personas intersex pueden identificarse como intersex, como hombres, como mujeres, como ambos o como ninguno de los dos, ya este término intersex, es un término paraguas que abarca dicha diversidad corporal (Gómez, 2012).

\section{La orientación sexual como identidad de género y expresión de género}

El género es una categoría de análisis que permite conocer la forma como se construye lo femenino y lo masculino en un tiempo y en un espacio determinado y las relaciones que se establecen entre mujeres y hombres. El género se refiere a las ideas y expectativas (normas) extensamente compartidas con respecto a mujeres y hombres. Estas incluyen las ideas sobre características y habilidades "típicamente" consideradas 
La violencia contra las personas sexo-género diverso su tratamiento en el sistema jurídico venezolano

masculinas y femeninas y expectativas comúnmente compartidas acerca de cómo deben comportarse las mujeres y los hombres en diversas situaciones como debe ser su orientación sexual.

La afirmación anterior determina que la orientación sexual de una persona es independiente del sexo que le asignaron al nacer, e independiente de su identidad de género.Sin embargo, la orientación sexual de los individuos constituye un componente fundamental de la vida privada de las personas y que existe una clara conexión entre la orientación sexual y el desarrollo de la identidad y el plan de vida de cada persona, incluyendo su personalidad, y las relaciones con otros seres humanos.Partiendo de los supuestos anteriores, la orientación sexual viene a ser definida como la capacidad de cada persona de sentir una profunda atracción emocional, afectiva y sexual por personas de un género diferente al suyo, o de su mismo género, o de más de un género, así como a la capacidad de mantener relaciones íntimas y sexuales con estas personas".

Resulta asimismo interesante definir a la identidad de género como la vivencia interna e individual del género tal como cada persona la siente profundamente, la cual podría corresponder o no con el sexo asignado al momento del nacimiento, incluyendo la vivencia personal del cuerpo (que podría involucrar la modificación de la apariencia o la función corporal a través de medios médicos, quirúrgicos o de otra índole, siempre que la misma sea libremente escogida) y otras expresiones de género incluyendo la vestimenta, el modo de hablar y los modales" contemplado en los principios de Yogyakarta del año 2006 (Gómez, 2012).

Finalmente, la expresión de género hace referencia a la manifestación externa del género de una persona, a la noción de aquellos elementos que constituyen las normas masculinas o femeninas correctas. Lo hoy se han traducido a las fuentes de abusos contra los derechos humanos sexuales de las personas que no encajan o no se ajustan a estos modelos estereotípicos de lo masculino o lo femenino. Entonces la expresión de género es visible y puede ser una fuente de identificación, especialmente 
cuando a través de características como la vestimenta, los manierismos y las modificaciones corporales, se subvierten expectativas tradicionales de expresión de género (Hammarberg, 2009).

\section{La violencia contra las personas sexo-género diverso entendiendo su origen y sus consecuencias}

Antes empezar a definir lo que es violencia contra las personas por su diversidad género-sexual, se hace necesario definir o entender las diferencias de conceptos como sexo y género, la diferencia entre los conceptos sexo y género radica en que el primero se concibe como un hecho biológico y el segundo como una construcción social. Es decir, al hablar de sexo se hace referencia a las diferencias biológicas entre el hombre y la mujer, no así cuando se hace referencia al término género el cual refiere a las identidades, las funciones y los atributos construidos socialmente y culturalmente de la mujer y el hombre y al significado social y cultural que se atribuye a esas diferencias biológicas (Fernández, 1991).

Por otro lado, entender el significado del acrónimo LGBTI, que se usa como término colectivo para referirse a las personas Lesbianas, Gays, Bisexuales, Trans (el término trans se refiere a travestis, transexuales y transgénero) e Intersexuales.

Sobre los aspectos del concepto de identidad de género; que no es más que la vivencia interna e individual del género tal como cada persona la experimenta profundamente, la cual podría corresponder o no con el sexo asignado al momento del nacimiento, incluyendo la vivencia personal del cuerpo (que podría involucrar la modificación de la apariencia o la función corporal a través de técnicas médicas, quirúrgicas o de otra índole, siempre que la misma sea libremente escogida) y otras expresiones de género, incluyendo la vestimenta, el modo de hablar y los modales (Marcuello, 1999).

En el Informe técnico (Organización Mundial de la Salud, 1998), sobre la violencia contra la mujer como un tema de salud prioritario este conceptualiza a la 
La violencia contra las personas sexo-género diverso su tratamiento en el sistema jurídico venezolano

violencia desde una perspectiva con múltiples dimensiones y connotaciones, que incluye el uso intencional de fuerza, poder físico, o amenazas, en contra de uno mismo, otra persona, o en contra de un grupo o comunidad en este caso el género-sexo diverso, cuyo resultado desemboca con alta probabilidad en lesiones, muerte, secuelas psicológicas, o mal comportamiento.

Laviolencia apunta en una comprensión como un fenómeno social, en contraposición con la violencia entendida como un hecho aislado. El concepto de violencia por prejuicio de genero intersex, para entender la violencia que es ejercida contra las personas que se perciben como trasgresoras de las normas tradicionales de género, del binomio hombre/mujer, y cuyos cuerpos difieren de los cuerpos estándar conocido es decir femeninos y masculinos" (Gómez, 2012).

La violencia basada en el género-sexo diverso se ha convertido en un término general para cualquier daño que se cometa contra una persona, y que resulte de las desigualdades de poder que se basan en los roles de género. Es un tipo de violencia que se puede clasificar de diferentes formas que va desde la violencia física o psicológica ejercida contra cualquier persona sobre la base de su sexo o género que impacta de manera negativa su identidad y bienestar social, físico o psicológico.

En el ordenamiento jurídico interno venezolano cuando se viola el derecho a la integridad personal, debido a la desigualdad de género o sexo, se viola lo estipulado en el articulado de la Convención Americana Sobre Derechos Humanos (1969), los cuales fueron ratificados en el informe temático aprobado y emitido en el año 2015 sobre la violencia en contra de las personas LGBTI, que se exponen en los artículos $5^{\circ}$ el cual reza que: Toda persona tiene derecho a que se respete su integridad física, psíquica y moral. Asimismo, en el artículo $7^{\circ}$ expone: Toda persona tiene derecho a la libertad y a la seguridad personal. Los cuales son adoptados en el ordenamiento jurídico venezolano según el artículo $\mathbf{2 3}^{\circ}$ del texto constitucional como parte del derecho interno territorial (Melet y Melet, 2006). 
Por otro lado, la oficina del alto comisionado de las Naciones Unidas para la protección de los derechos humanos, emplea este término para distinguir la violencia común de aquella que se dirige a individuos o grupos sobre la base de su género. Entonces la violencia de género, es entendida como todo acto de agresión, física o psíquica, basado en la superioridad de un sexo sobre otro. Entonces se puede establecer que todo acto de violencia basado en la pertenencia al sexo-género diverso que tenga o pueda tener como resultado un daño o sufrimiento físico, sexual o psicológico (Maqueda, 2006).

Considerándose que la violencia física puede tener una escalada tan elevada al punto de dejar a la víctima gravemente herida o, puede conllevar a la muerte. Los hombres gais, o aquellos percibidos como tales, fueron más propensos a ser asesinados con armas blancas y en espacios privados, tales como el hogar de la víctima o ataques multitudinarios "Grandes multitudes realizando barricadas, lanzando objetos (tales como piedras y cócteles molotov), o instando al linchamiento de hombres gais (Gómez, 2012).

No así para la violencia fisca contra el grupo de mujeres lesbianas que son víctimas de mal denominada "violaciones sexuales correctivas" o violaciones con el objetivo de sancionarlas y castigarlas por su orientación sexual. También son víctimas a ataques colectivos por demostraciones públicas de afecto; ataques con ácido e internamiento forzado en centros que ofrecen "modificar" su orientación sexual

En cuanto la violencia contra el grupo de personas transgénero, en especial y particularmente contra las mujeres trans, se resume como el resultado de una combinación de múltiples factores que van desde la exclusión, la discriminación y violencia intrafamiliar, escolar y social en general. Las personas trans con expresión de género femenina fueron más propensas a ser asesinadas con armas de fuego, y sus cuerpos tienden a ser encontrados en las calles u otros espacios públicos, y en ocasiones en situaciones vinculadas con el trabajo sexual (Cabral, 2003). 
La violencia contra las personas sexo-género diverso su tratamiento en el sistema jurídico venezolano

. Estos casos en el Código Penal venezolano promulgado por la Asamblea Nacional (2005) están tipificados en el Título IX Delitos contra las personas, en el Capítulo I, artículo $\mathbf{4 0 8}^{\circ}$; así como en el Capítulo II de las lesiones personales, artículo415 ${ }^{\circ}$. También lo tipifica la Ley Orgánica de Igualdad y Equidad de Género promulgado por la Asamblea Nacional (2010).

En las personas intersex; lesbianas, gais, bisexuales, trans e intersex (LGBTI), estas pueden ser particularmente vulnerables a la violencia sexual, en donde una de las razones de esta vulnerabilidad se genera por el hecho de que las orientaciones sexuales e identidades de género diversas desafían las nociones tradicionales de la sociedad sobre el sexo, la sexualidad y el género.

Sobre las violaciones y actos de violencia sexual cometidos contra personas intersex, son producto de que en el "imaginario social" estos tipos de abuso sexual buscan "curar los cuerpos intersex," las mal llamadas "Violaciones Correctivas" dentro de este grupo, los hombres gais son los más afectados, las mujeres lesbianas y bisexuales son particularmente vulnerables a la violencia sexual. El concepto mismo de "violación correctiva" es incoherente y deplorable, dado que todo intento de "corregir" un aspecto fundamental de la identidad de un ser humano a través de la violencia es incompatible con la dignidad humana (Becerra-Fernández y col, 2010).

El propio Estado y sus instituciones son promotores de violencia hacia el grupo de personas LGBTI, sobre todo por agentes estatales encargado por velar por la seguridad de todos los ciudadanos. Violencia que puede ir desde la tortura y tratos crueles, inhumanos y degradantes (Gómez, 2012).

El involucramiento de los órganos judiciales (policía) y otros agentes estatales de seguridad en actos de discriminación y violencia contra personas LGBTI conduce a que las personas crean que pueden atacar impunemente a personas con orientaciones sexuales, identidades y expresiones de género diversas.

Casos en los que agentes de la policía no sólo ejercen violencia, sino que incitan a otros a atacar a personas LGBTI, o son indiferentes hacia la violencia 
perpetrada por terceras personas. La policía y otras fuerzas de seguridad legalmente facultados para mantener el orden público comparten las mismas actitudes y prejuicios contra personas LGBTI que prevalecen en la mayoría de la sociedad.

La violencia ocurre durante todas las etapas de la custodia policial, incluyendo la aprehensión, el transporte en vehículos policiales y en las instalaciones de las estaciones de policía y centros de detención de privación de libertad.

Entonces en el marco legal venezolano en la Constitución Nacional promulgada por la Asamblea Nacional (1999) esta prohíbe la Violencia de una persona debido a su orientación sexual, norma contenida en el Título III, Capítulo I, de los Derechos Humanos y Garantías y de los Deberes, en el artículo $\mathbf{2 1}^{\circ}$ al prohibir la discriminación de toda persona y establecer la igualdad de estas antes la ley, así como en el Artículo $27^{\circ}$ del derecho a ser protegido y amparados por los órganos de administración de justicia, y finalmente en el artículo $\mathbf{5 5}^{\circ}$ se recoge los derechos constitucionales a la integridad personal. Por otra parte, el artículo $\mathbf{4 6}^{\circ}$ numeral 4 de la constitución expone: Todo funcionario público o funcionaria pública que, en razón de su cargo, infiera maltratos o sufrimientos físicos o mentales a cualquier persona, o que instigue o tolere este tipo de tratos, será sancionado o sancionada de acuerdo con la ley.

Así también surge la violación de los derechos humanos contra personas intersex ejercida por los profesionales de la salud, la cual se debe a que sus cuerpos difieren del estándar corporal "femenino" y "masculino". Niñas y niños intersex son sometidos a intervenciones, incluyendo cirugías para modificar la apariencia de sus genitales, las cuales no son médicamente necesarias. En algunos casos se realiza sin consentimiento de padres y madres, y en otros casos familiares optan por intervenciones de "normalización" genital con base en desinformación o coerción (Vega y col, 2011). 
La violencia contra las personas sexo-género diverso su tratamiento en el sistema jurídico venezolano

Las cirugías y otras intervenciones que no son necesarias para preservar la vida o la salud no deben ser realizadas jamás sin el consentimiento libre e informado de la persona intersex a ser intervenida.

Otras formas de violencia en la prestación de servicios de salud, es el maltrato, el hostigamiento e incluso la violencia física son parte de la experiencia de las personas LGBT que buscan atención médica. Un caso extremo de negativa de tratamiento médico fue el de Robert Eads, un hombre trans estadounidense al que le diagnosticaron cáncer de ovarios. Según se reporte, al menos doce profesionales de la salud se rehusaron a darle tratamiento por temor a que "el tratamiento de este caso de variación de género pudiera dañar la reputación de sus prácticas médicas (Hammarberg, 2009).

Con respecto a las personas intersex, el principio del consentimiento previo, libre e informado es de la mayor importancia y debe guiar toda decisión relacionada con las cirugías, procedimientos, tratamientos hormonales y cualquier otro tratamiento médico de personas intersex. La esterilización involuntaria de las personas intersex representa una grave violación de derechos humanos.

Según se especifica en La Norma Oficial para la Atención Integral de la Salud Sexual y Reproductiva, las mujeres tienen derecho a la información completa y precisa sobre todos los tratamientos y procedimientos médicos o quirúrgicos que se le pretendan aplicar y para tomar la decisión que más crea conveniente, con clara, suficiente y amplia información, que no es otra cosa que el derecho al consentimiento previo informado, según el artículo $\mathbf{4 6}^{\circ}$ Constitución Bolivariana, junto al artículo $\mathbf{7 2}^{\circ}$ numeral 4 del Código de Deontología Médica, en el derecho del paciente a: Recibir la información necesaria para dar un consentimiento válido (libre), previo a la aplicación (Vega y col, 2011).

Asimismo, el Código de Deontología Médica Venezolano aprobado durante la CXXXIX reunión extraordinaria de la Federación Médica Venezolana (2004) esgrime en su artículo $\mathbf{5 5}^{\circ}$ sobre que: La anticoncepción quirúrgica permanente es 
permitida cuando se produce como consecuencia inevitable de una terapéutica encaminada a tratar o prevenir un estado patológico grave.

Las cirugías y otras intervenciones médicas que no son necesarias según criterios médicos deben ser postergadas hasta que las personas intersex puedan decidir por sí mismas.

Los Estados no recopilan datos sobre la prevalencia de estas cirugías y demás intervenciones médicas en personas intersex, lo cual invisibiliza la problemática y evita un abordaje efectivo. Es vital que los Estados den apoyo a las personas intersex y sus familias a través de equipos interdisciplinarios durante todas las etapas del desarrollo, desde la infancia, durante la niñez y adolescencia, hasta la adultez.

Los niños, niñas y adolescentes que son lesbiana, gais, bisexuales, transexuales e intersex, (LGBTI) o que son percibidos como tales, enfrentan estigmatización, discriminación y violencia por su orientación sexual o identidad de género real o percibida, o porque sus cuerpos difieren de las definiciones socialmente aceptadas de cuerpos femeninos y masculinos.

Por lo que la Organización de la Naciones Unidas a través del Fondo de las Naciones Unidas para la Infancia (UNICEF), revela que el alcance de la discriminación y violencia por su orientación sexual o identidad de género incluye: Aislamiento de los compañeros en la escuela, en la casa o en la comunidad; marginalización y exclusión de servicios esenciales como educación y asistencia médica; abandono por parte de la familia y la comunidad; acoso escolar o matoneo (bullying) e intimidación y, violencia física y sexual, incluyendo violaciones sexuales correctivas (Hammarberg, 2009).

Hay casos en los que los padres, madres u otros miembros de la familia ejercen violencia física contra los niños, niñas y adolescentes, porque les perciben como no conformes con el género, lesbianas, gais o bisexuales. La intención de esta violencia es "corregir" a los niños, un método brutal conocido como "sacar el gay con una paliza" (beat the gay out). La autoridad que se reconoce a la familia no implica 
La violencia contra las personas sexo-género diverso su tratamiento en el sistema jurídico venezolano

que ésta pueda ejercer un control arbitrario sobre el niño, niña o adolescente, que pudiera acarrear daño para la salud y el desarrollo del niño, niña o adolescente. (Aguilar, 2015).

Violencia en los entornos educativos "niños, niñas y adolescentes LGBT sufren de acoso escolar a manos de sus compañeros o compañeras, y maestros/as o profesores/as, lo cual conlleva a la deserción escolar. Incluso a algunos se les niega el ingreso escolar, o son expulsados y expulsadas de sus escuelas debido a su orientación sexual o identidad de género real o percibida”.

Por otra parte, ciento de jóvenes LGBTI son sometidos a las llamadas "terapias" con la finalidad de "modificar" su orientación sexual o identidad de género. Estas terapias son dañinas, contrarias a la ética, carecen de fundamento científico, son ineficaces y podrían constituir una forma de tortura. "Ante discriminación y vulneración de sus derechos, jóvenes LGBTI e intersex necesitan reconocimiento y protección”.

La persona con orientación sexual genero diversas que se encuentran bajo tratamiento mal llamado correctivo son encerrada o internada en un centro "clínica de deshomosexualización", la mayoría de las veces en contra de su voluntad o por medio de engaños, y sometida a regímenes muy estrictos, que suelen incluir tratos inhumanos o degradantes e incluso abusos sexuales como parte del "procedimiento" para tratar de cambiar su orientación sexual o identidad de género (Becerra-Fernández y col, 2010).

La existencia de estos centros para el tratamiento de personas LGBTI en países como Ecuador, Perú, República Dominicana, Estados Unidos, entre otros.

En el ordenamiento jurídico legal venezolano el texto constitucional bolivariano promulgado por la Asamblea Nacional (1999), este hace referencia en el artículo $46^{\circ}$ numeral 3 sobre el consentimiento de las personas este expone que: "Ninguna persona será sometida sin su libre consentimiento a experimentos 
científicos, o a exámenes médicos o de laboratorio, excepto cuando se encontrare en peligro su vida o por otras circunstancias que determine la ley" (Vega y col, 2011).

La violencia social, en muchos casos, la discriminación y la violencia que enfrentan las personas LGBTI por su orientación sexual e identidad de género es lo que les obliga a migrar, lo que a su vez puede conducir a diversas formas de discriminación contra estas personas en países de tránsito y destino.

Las solicitudes de la condición de refugiado con base en la orientación sexual y/o identidad de género comúnmente son analizadas bajo el fundamento de "pertenencia a determinado grupo social".

Los marcos internacionales en materia de asilo no toman en consideración las circunstancias específicas de las personas LGBTI, y los requisitos y el nivel de evidencia requeridos para un refugiado o un solicitante de asilo son a menudo inalcanzables para las personas LGBTI.

En muchas partes del mundo, las personas experimentan violencia y persecución debido a su orientación sexual real o percibida o su identidad de género Las personas sexo-genero diverso que huyen de sus países de origen, por esta causa deben tener por lo tanto siempre tener acceso a mecanismo de protección.

La denominación de una persona como lesbiana, gais, bisexual, transgenero o intersex (LGBTI) asegura el reconocimiento legal de la orientación sexual o de la identidad de género como condición esencial de la persona para su protección.

La discriminación que sufren las personas por su orientación sexual o identidad de género se manifiesta como la distinción, exclusión, restricción, o preferencia no justificada que tiene por objeto o por resultado anular o menoscabar el reconocimiento, goce o ejercicio en condiciones de igualdad de sus derechos y libertades.

Los oficiales que toman la decisión de determinación de la condición de refugiado no pueden basarse en presunciones estereotipadas de las personas LGBTI. 
La violencia contra las personas sexo-género diverso su tratamiento en el sistema jurídico venezolano

Es por esto que según el informe de la Oficina del Alto Comisionado de las Naciones Unidas para los Refugiados (ACNUR, 2002), expone en las directrices sobre la solicitud de la condición de refugiados relacionado con la orientación sexual y/o la identidad de género que las autoridades migratorias de algunos países consideran que todos los hombres gais son afeminados; que si una mujer lesbiana o un hombre gais anteriormente estuvieron en una relación sexual diferente, incluso casados y con hijos, él o ella no son realmente gais o lesbiana; que las personas bisexuales deben sentir atracción por ambos sexos al mismo tiempo o sentir igual atracción por hombres y mujeres, entre otros; no todas las personas trans eligen recibir tratamiento médico o modificar su apariencia externa, y como tal, es importante para los oficiales adjudicadores de la condición de refugiado, evitar el énfasis excesivo en cirugías de afirmación sexual o modificaciones corporales.

Mujeres trans son alojadas en centros de detención migratoria con la población del sexo masculino, aumentando su vulnerabilidad a ser sometidas a actos de violencia sexual. La CIDH considera que la decisión sobre dónde alojar a las personas trans debe realizarse caso por caso, con el debido respeto a su dignidad personal, y siempre que sea posible, luego de previa consulta con las personas trans.

La violencia mediática y simbólica contra las personas LGBTI se ve reforzada por la diseminación de "discursos de odio" dirigidos a esta comunidad en distintos contextos, incluyendo en debates públicos, manifestaciones en contra de eventos como las marchas del orgullo, en medios de comunicación y en Internet.

En la Ley Orgánica sobre el Derecho de las Mujeres a una Vida Libre de Violencia promulgada por la Asamblea Nacional (2007) en el artículo $\mathbf{5 3}^{\circ}$, que trata sobre la ofensa pública por razones de género, este expresa que: El o la profesional de la comunicación o que, sin serlo, ejerza cualquier oficio relacionado con esa disciplina, y en el ejercicio de ese oficio u ocupación, ofenda, injurie, denigre de una mujer por razones de género a través de un medio de comunicación, deberá indemnizar a la víctima de violencia con el pago de una suma no menor a doscientas 
(200 U.T.) ni mayor de quinientas unidades tributarias (500 U.T.) y hacer públicas sus disculpas por el mismo medio utilizado para hacer la ofensa y con la misma extensión de tiempo y espacio

La evidencia demuestra que cuando ocurren crímenes contra las personas LGBTI, con frecuencia están precedidos de un contexto de elevada deshumanización y discriminación. Es por esta situación que en su informe temático (2015), la Comisión Interamericana de Derechos Humanos conocidas por su sigla CIDH, sobre la situación de violencia contra las personas por orientación sexual o por su identidad de género en Venezuela, reitera que el país sureño no cuenta con una ley que obligue al Estado a garantizar y proteger el derecho a la igualdad y no discriminación de las personas LGBTI, en cuanto a la promoción y protección del derecho a la libertad de expresión que debe conjugarse con esfuerzos para combatir la intolerancia, la discriminación, el discurso de odio y la incitación a la violencia.

Por último, la violencia producto de la intersección con otros grupos. Las experiencias de personas lesbianas, gais, bisexuales, trans e intersex frente a la violencia es de naturaleza muy diversa. Esta diversidad es el resultado de diferentes circunstancias y características personales y en particular, de la existencia de ciertos factores que hacen a las personas LGBTI especialmente vulnerables a la violencia, o que empeoran las consecuencias de este tipo de violencia.

Sobre la violencia racial la CIDH, ha recibido información preocupante sobre los altos niveles de discriminación y violencia contra personas lesbianas, gais, bisexuales y trans (LGBTI descendencia africana) de y otras afectadas por la discriminación racial.

Las personas LGBTI y Queer de color son más propensas a experimentar la violencia perpetrada por sus parejas. Las personas trans de color son seis veces más propensas a experimentar violencia a manos de la policía, al compararlas con personas cisgénero blancas en Estados Unidos (Gómez, 2008). 
La violencia contra las personas sexo-género diverso su tratamiento en el sistema jurídico venezolano

La CIDH cuenta con la información sobre el impacto negativo de la colonización en las sexualidades ancestrales y espirituales de personas indígenas. De acuerdo a la información suministrada, la colonización resultó en la supresión de las sexualidades no normativas entre las personas indígenas. Esto tuvo consecuencias devastadoras, incluyendo la falta de aceptación de personas con sexualidad nonormativas dentro de sus propias sociedades, las lesiones auto-infligidas y el suicidio.

Asimismo, la violencia motivada por su inclinación religiosa, en ocasiones, ataques contra personas LGBTI o aquellas percibidas como tal, son motivados por la religión, particularmente los ataques dirigidos contra hombres gay jóvenes.

En Venezuela la sexo-genero diversidad no es considerada un delito por lo tanto se puede deducir que es legal. En el ordenamiento legal venezolano propugna como valores superiores; la vida, la libertad, la igualdad, la integridad y el libre desarrollo de la personalidad, entre otros valores que tiene carácter legal debido a través de promulgación de leyes por la Asamblea Nacional como: la Constitución Bolivariana (Asamblea Nacional, 1999), el Código Penal (Asamblea Nacional ,2005), Código Orgánico Procesal Penal (Asamblea Nacional, 2012), Ley Orgánica para la Protección de Niños, Niñas y Adolescentes (Asamblea Nacional, 2007a) y la Ley Orgánica sobre el Derecho de las Mujeres a una Vida Libre de Violencia (Asamblea Nacional, 2007b), y sobre todo el artículo $\mathbf{8}^{\circ}$ de la Ley Orgánica de Igualdad y Equidad de Género (Asamblea Nacional, 2010) que expone.

"Toda persona tiene el derecho a ejercer la Orientación e Identidad Sexual de su preferencia, de forma libre y sin discriminación alguna. En consecuencia, el Estado reconocerá las asociaciones de convivencia constituidas entre dos personas del mismo sexo, por el mutuo acuerdo y el libre consentimiento, con plenos efectos jurídicos y patrimoniales. Quien en ejercicio de la libertad a que se refiere el presente artículo cambiare de género por causas quirúrgicas o de otra índole tiene derecho al reconocimiento de su identidad y la expedición o modificación de los documentos asociados a la identificación... Asimismo, el estado garantizará los medios médicos asistenciales que 
sean necesarios para su cabal inserción y reconocimiento social en condiciones de igualdad."

Entonces por lo antes narrado es necesario incluir y establecer cuáles son las obligaciones básicas legales de los Estados, como Venezuela con respecto a la protección de los derechos humanos de las personas LGBTI, asimismo se debe incluir en una propuesta futura de reforma de la Ley Orgánica de Igualdad y Equidad de Género (Asamblea Nacional, 2010) estas cinco propuestas como nuevas obligaciones: 1. Proteger a las personas contra la violencia homofóbica y transfóbica. Incluir la orientación sexual y la identidad de género como características protegidas en leyes sobre delitos causados por el odio.

2. Prevenir la tortura, así como los tratos crueles, inhumanos y degradantes de las personas LGBTI privadas de libertad, prohibiendo y sancionando tales actos y garantizando que las víctimas reciban una reparación.

3. Derogar inmediatamente las leyes que penalizan la homosexualidad, incluyendo todas las leyes que prohíben relaciones sexuales con consentimiento entre adultos del mismo sexo. Asegurarse de que los individuos no sean arrestados o detenidos por motivos de orientación sexual o identidad de género.

4. Prohibir la discriminación por motivos de orientación sexual e identidad de género. Promulgar leyes extensas que incluyan la orientación sexual e identidad de género como motivos prohibidos de discriminación tanto en la esfera pública como en la privada.

5. Preservar la libertad de reunión, expresión y asociación pacifica para las personas LGBTI.

No cabe duda que la violencia de género supone una situación legal de gran envergadura, que se complica cuando solo es valorada desde el enfoque sociocultural y no desde el enfoque jurídico-legal (Vega y col, 2011). 
La violencia contra las personas sexo-género diverso su tratamiento en el sistema jurídico venezolano

\section{La violencia contra las personas sexo-genero diverso su tratamiento en el sistema penal venezolano}

La sexualidad humana había representado hasta hace mucho tiempo un tema tabú, pero lo dejo de ser hasta hace muy poco, cuando en las instituciones encargada de los derechos humano sobre todo los que tratan el tema de la sexualidad y la diversidad sexual orientada en la llamada diversidad de género. Entendiéndose entonces como personas con sexo-género diverso, término acuñado en las diferentes exposiciones sobre los derechos sexuales de los individuos que reconoce la existencia de una multiplicidad de vidas en la sociedad y una variedad de orientaciones, expresiones e identidades que contienen cargas afectivas, de género y sexo, nombrados con el acrónimo LGBTI.

En el sistema jurídico legal venezolano, la Constitución Bolivariana, promulgada por la Asamblea Nacional (1999), estableces las bases fundamentales que amparan y protegen los derechos para la igualdad y la equidad de género. El texto constitucional incluye una visión sobre género que se expresa desde el preámbulo hasta las disposiciones finales, con una participación protagónica y corresponsabilidad, en donde se reconocen los principios de igualdad y equidad, validando entre hombres y mujeres en el ejercicio y el acceso al trabajo, a sus derechos sexuales, contenido en los artículos $\mathbf{2 1}^{\circ}, \mathbf{7 5}^{\circ}, \mathbf{7 6}^{\circ}, \mathbf{7 7}^{\circ}, \mathbf{7 8}^{\circ}, \mathbf{8 0}^{\circ}$ y $\mathbf{8 8}^{\circ}$ del texto magno venezolano.

Sin embargo, cuando se hace referencia a la sexo-genero diversidad, el ordenamiento legal venezolano, en cuanto al tratamiento legal en contra de la violencia contra la condición sexo-genero diverso es decir contra las personas intersex (LGBTI), está enfocado en hacer caso omiso a esta situación bien sea por ignorancia o por omisión de la poca normativa legal existente que trata la temática en cuestión, cuando una persona intersex LGBTI, sufre algún tipo de violencia sobre todo física debido a su orientación sexual o de género y acude algún centro médico hospitalario, el personal salud principalmente los médicos desconocen deque tiene que hacer la 
denuncia y emitir un parte de lesiones como lo expresa el Código de Instrucción Médico Forense decretado por el Congreso de los Estados Unidos de Venezuela (1878),aún vigente en el artículo $9^{\circ}$ que expone: Siempre que un facultativo sea llamado para asistir un herido lo pondrá en conocimiento del Juez local o de cualquier otra autoridad de substanciación. El cual debe ser enviado al Fiscal de guardia para ponga en conocimiento al tribunal en materia de violencia de genero de un hecho que puede ser constitutivo de delito.

Es por esto que la mayoría de las ocasiones los demandantes/supervivientes de violencia producto de la sexo-genero diversidad suelen demorar al momento de hacer la respectiva denuncia, dichos retrasos pueden ser motivados por diversas razones, entre las cuales se puede mencionar: El temor de los demandante/superviviente a sufrir estigmatización, humillación, falta de credibilidad y represalias; dependencia financiera o emocional del autor del acto violento; y a la falta de confianza en las instituciones responsables, o por la inaccesibilidad o por ausencia de personal especializado.

Las demoras de las denuncias de violencia contra las personas intersex suelen interpretarse como una demostración de falta de credibilidad de los demandante/superviviente al sistema judicial venezolano.

Este parte le lesiones debe ser realizado por los médicos que atiendan al agredido o en su defecto por los médicos forenses (Peritos) adscrito al Cuerpo de Investigaciones Científicas, Penales y Criminalísticas, al Servicio Nacional de Medicina y Ciencias Forenses (SENAMECF), conformada por expertos para la atención de los casos de violencia de género, que emitirán los informes y experticias correspondientes en forma oportuna y expedita.

En otro orden de idea el marco legal venezolano en cuanto a los derechos de las personas sexo-genero diversos LGBTI por ser Venezuela parte del ordenamiento legal internacional según lo estipulado en el artículo $\mathbf{2 3}^{\circ}$ del texto constitucional como parte del derecho interno se acoge a lo que demanda los tratados, pactos o 
La violencia contra las personas sexo-género diverso su tratamiento en el sistema jurídico venezolano

convenciones internacional, es por esto que en la Novena Conferencia Internacional Americana (Declaración Americana de los Derechos y Deberes del Hombre, 1948), en el artículo $2^{\circ}$, estipula que: Toda persona tiene todos los derechos y libertades proclamados en esta Declaración, sin distinción alguna de raza, color, sexo, idioma, religión, opinión política o de cualquier otra índole, origen nacional o social, posición económica, nacimiento o cualquier otra condición, de esta forma se hace énfasis en el absoluto derecho que tiene cada ser humano a no ser discriminado por razón su orientación sexual o su identidad de género.

La comunidad LGBTI venezolana por omisión o comisión del Estado, son vulnerables a una serie de violaciones de derechos humanos, incluida la violencia homofóbica, el asesinato, la violación, la detención arbitraria y la discriminación generalizada en su lugar de trabajo, así como la discriminación en relación al acceso a servicios básicos como la vivienda y la asistencia médica y escolar, entre otras. En más de decena de países, las leyes catalogan como delito ser homosexual, lo que significa que millones de personas se hallan en riesgo de detención, encarcelamiento y, en algunos casos, la ejecución. En Venezuela la homosexualidad no se considera un delito según el código penal, pero por desconocimiento de la normativa muchas instituciones policiales la dejan ver como un delito.

Ya que como lo expone en su informe del año 2011, el Alto Comisionado de Naciones Unidas para los Derechos Humanos, en donde este ha señalado que la violencia contra la sexo-genero diversidad LGBTI, constituye una forma de violencia de género, impulsada por el deseo de castigar a quienes se considera que desafían las normas tradicionales o estandarizadas sobre el sexo y el género (Maqueda, 2006).

En muchos países del hemisferio las personas transgénero enfrentan barreras en la garantía a sus derechos humanos básicos incluyendo su derecho a vivir libres de discriminación y violencia, su derecho al acceso a la salud y al trabajo. Estas limitaciones se manifiestan en muchos aspectos la vida diaria de esta población, como los es la opción de cambiar de nombre y sexo en documentos de la identidad, obtener 
la libreta militar, tener acceso a la salud (incluyendo procesos de hormonización y transformaciones corporales), a la educación y al empleo.

La criminalización de las personas por sus orientaciones sexuales, identidades y expresiones de género, sobre aquellos comportamientos que no están normados o que no son percibidas como normales, específicamente las relaciones sexuales consensuales entre personas del mismo sexo. Así mismo existen legislaciones que discriminan a las personas LGBTI, que prohíben la entrada a países con base en la orientación sexual, leyes que establecen diferentes edades de consentimiento para tener relaciones sexuales entre personas del mismo sexo y de distinto sexo, y las sanciones en códigos militares o policiales a las relaciones sexuales entre personas del mismo sexo.

Otro aspecto a considerar son los delitos de corte penal sobre las personas LGBTI no conforme con el género, que criminalizan las relaciones sexuales consentidas entre personas del mismo sexo en privado, las cuales son arrastrada al sistema de justicia penal, criminalizando y sometiéndolas a más violencia. Son incompatibles con los principios de igualdad y no discriminación de acuerdo con el derecho internacional de los derechos humanos.

En el sistema penal venezolano no establece una definición de violencia de género, ni tampoco expone las herramientas conceptuales que permitan lograr una respuesta unívoca para todas las figuras incorporadas por la reforma legislativa.

La evolución legislativa que ha tenido el sistema legal venezolano, en cuanto a la problemática de la violencia contra las personas intersex LGBTI, es nula o insignificante, por lo que se hace necesario y conveniente legislar sobre este tema, para poder enfrentar y emprender la lucha contra el fenómeno de la violencia génerosexista.

En el derecho penal busca resguardar un bien jurídico que está bajo su tutela, que en este caso sería la vida o la integridad física o psicológica de las personas LGBTI, ya que este delito se estipula en el Código Penal venezolano promulgado por 
La violencia contra las personas sexo-género diverso su tratamiento en el sistema jurídico venezolano

la Asamblea Nacional (2005), como un delito contra las personas el cual esta regulado y tipificado en el Título IX, en el Capítulo I, artículo $\mathbf{4 0 8}^{\circ}$ numeral 1 , cuando se cause la muerte de la víctima con alevosía o por motivos fútiles o innobles. Así como en el Capítulo II de las lesiones personales, artículo $\mathbf{4 1 5}^{\circ}$. También lo tipifica la Ley Orgánica de Igualdad y Equidad de Género, por tanto, el bien jurídico protegido es la vida humana independiente como en cualquier homicidio, esto es, el ser humano en toda su integridad vital.La acción típica del delito consiste en matar o lesionar a las personas debido a su diversidad género-sexual LGBTI.

Con respecto a los sujetos del delito, hay que formular una distinción: Si se trata del homicidio de los ascendientes, descendientes o pareja, estamos ante un tipo especial de autor cualificado, en el sentido de que sólo puede ser sujeto activo del delito aquel que reúne la condición requerida normativamente.

En estos casos, el sujeto pasivo también debe ser algunas de estas personas LGBTI, ya sean ascendiente, descendiente o pareja. Si, en cambio, se tratara del homicidio de la ex-pareja o del conviviente, entonces estamos ante un delito común de sujetos indiferenciados. Tanto el autor como la víctima pueden ser cualquier persona.

Con arreglo al texto legal, el término "relación de pareja" al no exigir "convivencia" (mediare o no convivencia, dice la ley) debe ser entendido, mínimamente, como una relación meramente afectiva, que puede o no presuponer convivencia o vida en común. De manera que, de acuerdo a esta interpretación, tendrá la misma penalidad.

Es un delito doloso, de lo que no hay duda. El problema se presenta a la hora de determinar la posibilidad de concurrencia del tipo agravado mediando el dolo eventual.Tratándose de un delito de resultado material, la consumación coincide con la muerte del sujeto pasivo, sin importar que ella haya acaecido o no en un contexto de género o en el ámbito de una relación familiar. Basta con que concurran en el caso concreto los vínculos y relaciones establecidas normativamente, para que la muerte del sujeto pasivo conduzca a la agravante. La tentativa es admisible. 
Juan Carlos Araujo-Cuauro

Telos Vol. 20, No. 1 (2018). 129-158

\section{Conclusiones}

La violencia motivada contra las personas género-sexo diverso, constituye hoy en día a una violación a los derechos humanos de tercera generación como lo son los derechos sexuales. Esto se debe a que, en las legislaciones existentes en materia de protección de derechos sexuales, de equidad y de género son muy pocas las que hacen referencia a cerca de este derecho.

La violencia motivada contra las personas por su condición género-sexo diversidad, es una violencia que puede estar basada en prejuicios, ya para muchos se percibe como una transgresión a las normas tradicionales de género, o por otro lado se constituyen simplemente racionalizaciones o justificaciones de reacciones negativas, frente a expresiones de orientaciones sexuales o identidades de género no normativas que la sociedad asume para en si.

El sistema legal venezolano a través de sus instituciones, no le brinda, ni le protegen a los ciudadanos y ciudadanas que integran el grupo de personas sexo-género diverso LGBTI, su derecho a la diversidad sexual contemplado los tratados pactos y convenciones internacionales donde el Estado está suscrito.

Así mismo no han establecido directrices razonables, éticas y legales, que orienten la actitud de la sociedad en general hacia el derecho que tiene toda persona a manifestar abiertamente su orientación sexual basada en el género como parte de los derechos sexuales que son derechos humanos universales basados en la libertad inherente, dignidad e igualdad para todos los seres humanos.

Se puede constatar que en todo el mundo hay personas que comenten delitos en contra la vida y la integridad física o psicológica de las personas LGBTI, producto de la discriminación por su orientación sexual y suidentidad de género, que deben tener los correctivos y sanciones basados en las leyes penales, en donde el ámbito penal venezolano no escapa de esta cruda realidad existente. 
La violencia contra las personas sexo-género diverso su tratamiento en el sistema jurídico venezolano

\section{Referencias Bibliográficas}

ACNUR (2002). Directrices sobre la persecución por motivos de género. Extraído de http://www.acnur.org/t3/fileadmin/Documentos/BDL/2002/1753.pdf.

Consulta:12/02/17.

Aguilar Camacho, Mario Jesús. (2015). La transexualidad en México. El paradigma desde la patología al derecho humano de modificar la identidad. Revista de Bioética y Derecho,35, 3-17. Extraído de http://www.dx.doi.org/10.1344/rbd2015.35.14277 Consulta: 08/04/17.

Asamblea Nacional (2000). Constitución Nacional de la República Bolivariana de Venezuela. Gaceta Oficial 5.453 (Extraordinario). Venezuela.

Asamblea Nacional (2012). Código Orgánico Procesal Penal, según Gaceta Oficial No 5.930 Extraordinario del 4 de septiembre de 2009. Editorial Hermanos Vadell. Venezuela.

Asamblea Nacional (2005). Código Penal de Venezuela con Ley de Reforma Parcial, según Gaceta Oficial № 5.768. Editorial Hermanos Vadell. Venezuela.

Asamblea Nacional (2010). Ley Orgánica para la Equidad e Igualdad de Género en Venezuela Gaceta Oficial No 39.465. Venezuela.

Asamblea Nacional (2007a). Ley Orgánica para la Protección de Niños, Niñas Y Adolescentes Gaceta Oficial. 5.859 Extraordinaria. Venezuela.

Asamblea Nacional (2007b) Ley Orgánica sobre el Derecho de las Mujeres a una Vida Libre de Violencia (Gaceta oficial N ${ }^{\circ} 38.668$ del 23-04-07. Venezuela.

Becerra-Fernández Antonio, Lucio-Pérez María Jesús, Rodríguez-Molina José Miguel, Asenjo-Araque Nuria, Pérez-López Gilberto, Frenzi-Rabito María, Menacho Román, Miriam. (2010). Transexualidad y Adolescencia. Revista Internacional de Andrología. Elsevier Editorial System, 8(4), 143-186. Extraído de

http://www.sciencedirect.com/science/article/pii/S1698031X10700315

Consulta: 10/04/17.

Cabral, Mauro. (2003). Pensar la intersexualidad, hoy Cabral Incluido en "Sexualidades Migrantes, Género y Transgénero". Maffia, Diana (ed.). Editorial Feminaria: Buenos Aires, Argentina.

Congreso de los Estados Unidos de Venezuela (1878). Código de Instrucción Médico

Forense Gaceta Oficial 1443; Leyes y Decretos Reglamentarios de los Estados Unidos de Venezuela. Venezuela.

Convención Americana sobre Derechos Humanos.(2003).Conferencia especializada interamericana sobre derechos humanos. Extraído de https://www.oas.org/dil/esp/tratados_b32_convencion_americana_sobre_dere chos_humanos.htm Consulta: 18/04/17.

Declaración Americana de los Derechos y Deberes del Hombre (1948). Novena Conferencia Internacional Americana Bogotá, Colombia, 1948. Extraído de 
https://www.oas.org/dil/esp/Declaraci\%C3\%B3n_Americana_de_los_Derech os_y_Deberes_del_Hombre_1948.pdf Consulta: 18/04/17.

Federación Médica Venezolana (2003). Código de Deontología Médica. Aprobado durante la CXXXIX reunión extraordinaria de la Asamblea de la Federación Médica Venezolana realizada en Barquisimeto el 18 y 19 de octubre de 2003. Venezuela.

Fernández, Juan. (1991). Clarificación terminológica: El sexo, el género y sus derivados. Investigaciones Psicológicas, 9, 19-34. Ed Universidad Complutense Madrid.

Gómez Dueñas, María Catalina. (2012). Sexualidad y violencia. Crimines por prejuicio sexual en Cali. 1980-2000. Revista CS, 2(10), 169-205. Extraído de http://www.dx.doi.org/10.18046/recs.i10.1358 Consulta:10/03/17.

Gómez, María M. (2008). Capítulo 2: Violencia por prejuicio, La Mirada de los Jueces: Sexualidades diversas en la jurisprudencia latinoamericana. Tomo 2. Vol. 2. Editores, Red Alas. Bogotá, Colombia.

Hammarberg, Thomas. (2009). Derechos Humanos e Identidad de Género. Extraído de https://wcd.coe.int/ViewDoc.jsp?id=1621709\&Site=COE Consulta: $10 / 04 / 17$.

Informe técnico (1998). Violencia contra la mujer: un tema de salud prioritario. Organización Mundial de las Salud. Extraído de http://www.whoint/gender/violence/enviolence infopack1.pdf Consulta: 15/04/17.

Informe temático (2015): "Violencia contra Personas LGBTI en América. Aprobado por la Comisión Interamericana de Derechos Humanos. Extraído de http://www.oas.org/es/cidh/informes/pdfs/violenciapersonaslgbti.pdf Consulta: 20/03/17.

Lamas, Marta. (2002). Cuerpo: Diferencia Sexual y Género. Taurus; México.

Maqueda Abreu, María Luisa. (2006). La violencia de género: Entre el concepto jurídico y la realidad social. Revista Electrónica de Ciencia Penal y Criminología, 8(2), 1-13. $\quad$ Extraído de http://www.cienciaspenales.net/files/2016/09/2violencia_genero_maqueda.pdf. Consulta: 08/04/2017

Marcuello Franco, Ana Carmen, Elósegui Itxaso, María. (1999). Sexo, género, identidad sexual y sus patologías. Cuadernos de Bioética., 10(39), 459-477. Extraído http://www.facmed.unam.mx/deptos/familiar/compendio/Primero/I_SM_158180.pdf Consulta 14/04/17.

Melet Padrón, Anabel y Melet Padrón, Alejandro (2006). La Convención Americana sobre Derechos Humanos (Pacto de San José) y su influencia en el ordenamiento jurídico interno venezolano. Revista de la Ciencias Jurídicas y Políticas, 3, $\quad 117-137$. Extraído de 
La violencia contra las personas sexo-género diverso su tratamiento en el sistema jurídico venezolano

http://servicio.bc.uc.edu.ve/derecho/revista/3-2007/art\%204.pdf

Consulta:16/04/17.

Rey, Rodolfo. (2001). Diferenciación sexual embrio-fetal: De las moléculas a la anatomía. Revista chilena de anatomía, 19(1),75-82. Extraído de https://dx.doi.org/10.4067/S0716-98682001000100012. En fecha 10/04/2017.

Vega, Gabriela, Hidalgo, Dinora, \& Toro Merlo, Judith. (2011). Violencia basada en género desde la perspectiva médica. Revista de Obstetricia y Ginecología de Venezuela, 71(2), 88-97. Extraído de http://www.scielo.org.ve/scielo.php?script=sci_arttext\&pid=S004877322011000200003\&lng=es\&tlng=es Consulta 18/04/17. 